\title{
Is there a role for dietary salicylates in health?*
}

\author{
The late John Paterson ${ }^{1}$, Gwen Baxter ${ }^{1}$, James Lawrence ${ }^{1}$ and Garry Duthie ${ }^{2 \dagger}$ \\ ${ }^{1}$ Dumfries and Galloway Royal Infirmary, Bankhead Road, Dumfries, DG1 4AP, UK \\ ${ }^{2}$ Rowett Research Institute, Greenburn Road, Aberdeen AB21 9SB, UK
}

\begin{abstract}
Acetylsalicylic acid (aspirin ${ }^{\mathrm{TM}}$; 2-acetoxybenzoic acid) has been used for $>100$ years for pain relief and to treat inflammatory conditions and fevers. More recently, regular intake has been associated with decreased incidence of certain cancers, particularly colon cancer. After absorption aspirin is very rapidly hydrolysed to salicylic acid (2-hydroxybenzoic acid). The anti-cancer effects of aspirin may be a result of salicylic acid reducing the transcription of prostaglandin $\mathrm{H}_{2}$-synthase and thereby the synthesis of pro-inflammatory and potentiallyneoplastic prostaglandins. Salicylic acid is widely present in plants and functions as a hormonal mediator of the systemic acquired resistance response to pathogen attack and environmental stress. Thus, it is present in a large range of fruit, vegetables, herbs and spices of dietary relevance. Consequently, the recognised effect of consuming fruit and vegetables on lowering risk of colon cancer may be partly attributable to salicylates in plant-based foods. The present review discusses which types of fruit and vegetables are the richest source of salicylates and whether they are sufficiently released from the food matrix to modify the key cellular events associated with the pathogenesis of colon cancer.
\end{abstract}

Salicylic acid: Aspirin: Fruit and vegetables: Colon cancer

For $>100$ years aspirin ${ }^{\mathrm{TM}}$ (acetylsalicylic acid; Fig. 1) has been used to provide pain relief and to treat inflammatory conditions and fevers (Jeffreys, 2004). More recently, regular intake of aspirin has also been associated with a decreased incidence of some cancers, particularly colon cancer (Bosetti et al. 2001). Such epidemiological observations are now corroborated by results from several double-blind randomised placebo-controlled intervention trials (Baron et al. 2003; Benamouzig et al. 2003; Sandler et al. 2003) that indicate that daily consumption of a $75-80 \mathrm{mg}$ aspirin tablet can lead to a $40-50 \%$ decrease in the risk of developing colon cancer (as indicated by a reduction in colo-rectal adenomas). This apparent efficacy of aspirin is also supported by an ability to inhibit the development of aberrant crypt foci in the colon of animals and man (Craven \& DeRubertis, 1992; Reddy et al. 1993; Mahmoud et al. 1998; Shpitz et al. 1998, 2003); i.e. early dysplastic pathological lesions that may predict the risk of fulminant colon cancer (Fenoglio-Preiser \& Noffsinger, 1999). Aspirin is a prodrug, in that after absorption from the stomach and small intestine it is very rapidly hydrolysed to salicylic acid (2-hydroxybenzoic acid; Fig. 1) by carboxylases in the liver and blood, where it is tightly bound to plasma proteins and widely distributed to all tissues in the body (Needs \& Brooks, 1985). The serum half-life of aspirin is only $20 \mathrm{~min}$, whereas that of its major de-acetylated metabolite can range from $2 \mathrm{~h}$ to $30 \mathrm{~h}$ (Davidson, 1971). Consequently, it is more likely that the anti-carcinogenic effects of aspirin can be ascribed to salicylic acid than to the parent molecule.

Considerable epidemiological evidence suggests that regular consumption of fruit and vegetables decreases the risk of developing several cancers, including colon cancer (Riboli \& Norat, 2003). As plants contain natural salicylates they are likely to be present in a wide range of fruit, vegetables, herbs and spices of dietary relevance. Thus, it has been suggested that the recognised effects of consuming fruit and vegetables on lowering risk of colon cancer may be partly attributable to salicylates in plant-based foods (Paterson \& Lawrence, 2001). Accordingly, the present brief review considers whether dietary salicylates have a role in health by assessing which types of fruit and vegetables are the richest sources and whether they are released from the food matrix to allow biological effects. Possible mechanisms by which salicylates may modify the key cellular events associated with the pathogenesis of colon cancer are also discussed.

Abbreviation: PGHS-2, prostaglandin $\mathrm{H}_{2}$-synthase.

*This paper is dedicated to the memory of John Paterson.

$\uparrow$ Corresponding author: Professor Garry Duthie, fax +44 1224 716629, email G.Duthie@ rowett.ac.uk 


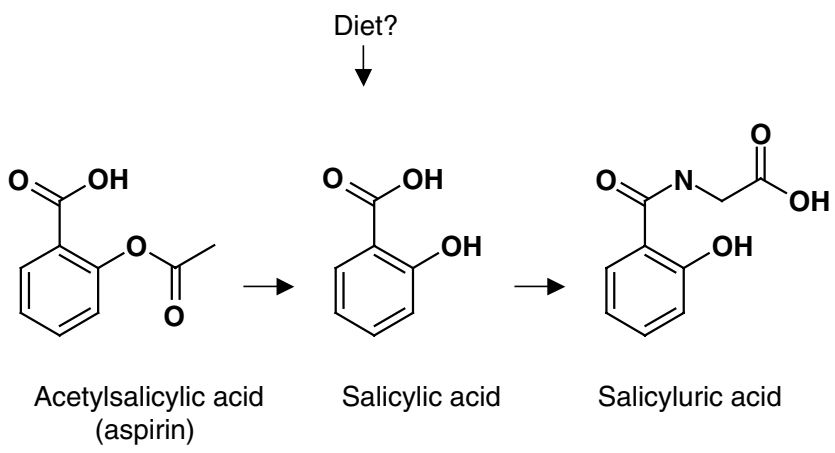

Fig. 1. Structures of acetylsalicylic acid (aspirin), salicylic acid and the major urinary metabolite, salicyluric acid.

\section{Salicylates in foods and dietary intakes}

Salicylic acid is a plant secondary metabolite largely generated by the phenylpropanoid pathway from transcinnamic acid and benzoic acid. It is central to the plant's systemic acquired resistance system, acting as a signalling molecule for the synthesis of specific proteins that increase resistance to pathogen attack. Other possible roles include stimulation of flowering, germination and growth regulation (Pierpoint, 2002). The use of willow (Salix spp.) and meadowsweet (Filipendula ulmaria) in ancient times to treat a variety of medical conditions through fever reduction and pain relief has been ascribed to their high content of salicylic acid and related compounds (Jeffreys, 2004). However, salicylic acid is also present in plants of dietary relevance, having been detected in many fruits and vegetables (Robertson \& Kermode, 1981) since being identified in strawberries at the beginning of the 20th century (Anon, 1903). Despite the ubiquitous presence of salicylic acid in plant-based foods, estimating dietary intakes remains problematical. For example, Swain et al. (1985) suggest that a normal diet could provide 10-200 mg natural salicylates/d, in contrast to Radtke et al. (1998) and Venema et al. (1996) who estimate daily intakes of only $0 \cdot 1-10 \mathrm{mg}$ and $0-5 \mathrm{mg}$ respectively. The wide range of salicylate values recorded for similar plant-based food items (Table 1) may reflect factors such as varietal differences, shelf-life and growing conditions or even methodology of determination. For example, higher salicylic acid contents of soups made from organicallygrown fruit and vegetables compared with corresponding conventionally-reared pesticide-treated products (Baxter et al. 2001) may reflect enhanced activation of the systemic acquired resistance response to pathogen insult. There are differences in sensitivities between the various methodologies used for salicylate determination. For example, UV spectrophotometric methods that rely on metal ions binding with phenol and carboxyl groups of salicylic acid (for example, see Nordic Committee on Food Analysis, 1999) could be confounded by reaction with structurally-related compounds, thus leading to overestimation of dietary intakes of salicylic acid (Wood et al. 2005). Consequently, values for salicylic acid contents of foods in earlier literature should perhaps be treated with caution. Studies using HPLC with alkaline- or acid-hydrolysis and compound validation by MS are
Table 1. Reported values for salicylate content of similar food items

\begin{tabular}{lcc}
\hline & $\begin{array}{c}\text { Total salicylates } \\
(\mathrm{mg} / \mathrm{kg}) \\
(\text { Swain } \text { et } \text { al. } \\
1985)\end{array}$ & $\begin{array}{c}\text { Total salicylates } \\
(\mathrm{mg} / \mathrm{kg}) \\
(\text { Venema } \text { et } \text { al. } \\
1996)\end{array}$ \\
Food & $5 \cdot 9$ & $0 \cdot 02$ \\
Apple & $14 \cdot 2$ & $0 \cdot 1$ \\
Canned apricot & $23 \cdot 9$ & $0 \cdot 02$ \\
Orange & $13 \cdot 6$ & $0 \cdot 7$ \\
Strawberry & $30 \cdot 6-50 \cdot 6$ & $0 \cdot 4$ \\
Currants & $66 \cdot 2-78 \cdot 0$ & $1 \cdot 0$ \\
Raisins & $7 \cdot 8$ & $0 \cdot 1$ \\
Cucumber & $5 \cdot 3$ & $0 \cdot 4$ \\
Tomato & 152 & $23 \cdot 8$ \\
Cinnamon & 2180 & $5 \cdot 5$ \\
Curry powder & 2030 & $3 \cdot 0$ \\
Paprika (hot powder) & 680 & $28 \cdot 4$ \\
Rosemary (Rosmarinus & & \\
$\quad$ officinalis; & & \\
$\quad$ dried powder) & & $12 \cdot 8$ \\
Thyme (Thymus & & \\
$\quad$ vulgaris; dried leaves) & 1830 & $19 \cdot 9$ \\
Oregano (Oreganum & & \\
$\quad$ vulgare; dried powder) & 660 & $0.3-7 \cdot 1$ \\
Red wine & & \\
\hline
\end{tabular}

preferred for the construction of dietary salicylate databases. Using data from such studies (Swain et al. 1985; Venema et al. 1996; Baxter et al. 2001), together with the application of a semi-quantitative food-frequency questionnaire (Scottish Collaborative Group food-frequency questionnaire version 7.0; Scottish Collaborative Group, 2005) for forty-one individuals (51-71 years), cautiously and provisionally provides estimates for daily intake of 9.9 (range 1-31) mg/d; G McNeill, G Munro and GG Duthie, unpublished results). This value is comparable with intakes of other dietary compounds with phenolic structures such as vitamin E, flavanones and flavonols (Duthie et al. 2003). However, salicylate intake is markedly increased by the consumption of foods containing spices (Table 1). For example, substantial amounts of salicylates are found in cumin, paprika and turmeric $(16290,1040$ and $3500 \mathrm{mg} / \mathrm{kg}$ respectively) and a portion of vindaloo curry (545 g) contains $94 \mathrm{mg}$ salicylate, which is similar to that of a low dose of aspirin (Baxter et al. 2005).

\section{Evidence for dietary uptake of salicylic acid}

Although there is some uncertainty concerning the quantitative estimation of the salicylate content of plant-based foods, evidence for dietary as opposed to pharmaceutical sources is suggested by the detection of salicylic acid and associated metabolites in plasma and urine of individuals not taking aspirin or related preparations (Paterson et al. 1998; Blacklock et al. 2001; Baxter et al. 2002). Moreover, serum (Fig. 2) and urinary concentrations of salicylates for vegetarians are significantly greater $(P<0 \cdot 001)$ than those for omnivores and overlap with those for individuals taking low-dose aspirin (serum salicylic acid concentrations are $0 \cdot 04-2 \cdot 47 \mu \mathrm{mol} / \mathrm{l}$ for vegetarians and $0.023-25.40 \mu \mathrm{mol} / \mathrm{l}$ for individuals taking $\leq 150 \mathrm{mg}$ aspirin/d; Blacklock et al. 2001; Lawrence et al. 


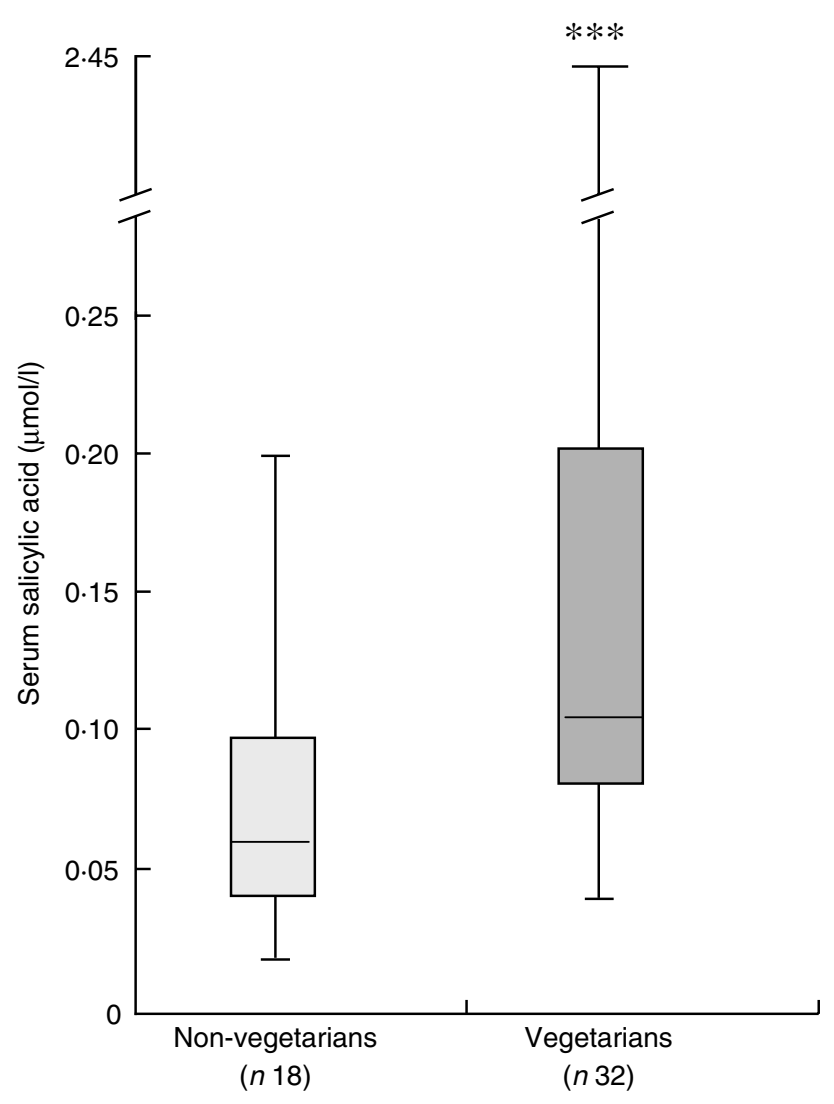

Fig. 2. Concentrations of salicylic acid in the serum of nonvegetarians $(\square)$ and vegetarians $(\square)$ not taking salicylate drugs. Values are medians $(-)$ with ranges represented by vertical bars and $95 \% \mathrm{Cl}(\square, \square)$. Median value is significantly greater for vegetarians than that for the non-vegetarians (Mann Whitney $U$ test): ${ }^{* \star *} P<0 \cdot 001$. (Adapted from Blacklock et al. 2001.)

2003), again suggesting substantial absorption from ingested fruit and vegetables. This finding is supported by the results of a placebo-controlled intervention study (Duthie et al. 2005) that show that daily consumption of cranberry juice containing $5 \mathrm{mg}$ natural salicylates is associated with a marked increase in salicylic acid and its major metabolite, salicyluric acid, in urine within 1 week of the intervention. In addition, consumption of a salicylate-rich vindaloo curry clearly results in increases in salicylic acid and salicyluric aid in plasma and urine respectively (Fig. 3).

\section{A role for dietary salicylates in the prevention of colon cancer?}

A general characteristic of the early stages of cancer development is a disregard by the cell of signals to stop proliferating and differentiating, and the autonomous generation of signals that promote growth. In the case of colon cancer this transition appears to arise from a stepwise accumulation of genetic changes initiated by mutations in the adenomatous polyposis coli tumour suppressor gene that normally blocks the signalling molecule, $\beta$-catenin. This step in turn may lead to the formation of complexes with transcription factors that activate numerous genes that

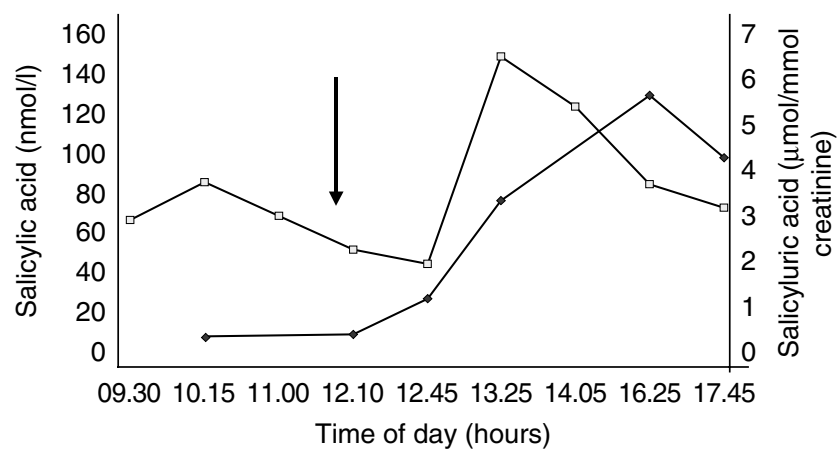

Fig. 3. Increases in salicylic acid in the serum ( $\square$ ) and salicyluric acid in the urine $(\bullet)$ of a subject before and after consuming a curry containing $80 \mathrm{mg}$ natural salicylates. $\downarrow$, Curry started.

stimulate cell proliferation or inhibit apoptosis (Hawk et al. 2004). How dietary salicylic acid may interfere with this process to reduce the risk of developing colon cancer is unclear. One possibility relates to the ability of aspirin to inhibit prostaglandin $\mathrm{H}_{2}$ synthase (PGHS-2) and thus prevent the conversion of arachidonic acid to potentially-tumourpromoting cyclic prostanoids. Unlike its acetylated form, which at pharmacological concentrations may reversibly bind to the active site of PGHS-2 hindering access to arachidonic acid, salicylic acid has little direct effect on the activity of the enzyme (Hare et al. 2003). However, at concentrations observed in the serum of vegetarians (Fig. 2) salicylic acid appears to inhibit PGHS-2 gene transcription, thus inhibiting PGHS-2 mRNA synthesis and promoter activity (Xu et al. 1999; $\mathrm{Wu}, 2000)$. It is, therefore, feasible that sufficient salicylates could be obtained from regular consumption of plant-based diets to decrease disease risk by PGHS-2 inhibition, although effects through PGHS-2-independent mechanisms also need to be considered.

\section{Conclusions}

Salicylic acid has anti-inflammatory and anti-neoplastic properties, is found in a wide range of fruit, vegetables, herbs and spices, and is absorbed from the food matrix into the circulation of human subjects. It has previously been unclear whether there is sufficient salicylate in foods to contribute to the recognised beneficial effects of a plant-based diet. Janssen et al. (1996) have concluded that the amounts of bio-available salicylates in a 'normal' diet are too low to affect disease risk. There is certainly great variability in the reported salicylate contents of foods, which may reflect varietal, environmental and analytical differences between studies. However, serum and urinary concentrations of salicylic and salicyluric acids respectively are greater in vegetarians than in nonvegetarians, and overlap with those for individuals consuming $\leq 150 \mathrm{mg}$ aspirin/d (Blacklock et al. 2001; Lawrence et al. 2003). Serum concentrations of salicylic acid for vegetarians can be $>2000 \mathrm{nmol} / \mathrm{ml}$ (Paterson \& Lawrence, 2001). This finding suggests that potentiallypreventative levels could be achieved by eating salicylic acid-rich foods, particularly as concentrations as low as 
$100 \mathrm{nmol} / \mathrm{ml}$ can inhibit the transcription of PHGS-2, an enzyme implicated in colon cancer pathogenesis.

\section{Acknowledgement}

GGD is grateful to the Scottish Executive Rural Affairs Department (SEERAD) for financial support.

\section{References}

Anon (1903) Salicylic acid in strawberries. Lancet ii, 1187. Baron JA, Cole BF, Sandler RS, Haile RW, Ahnen D, Bresalier R et al. (2003) A randomised trial of aspirin to prevent colorectal adenomas. New England Journal of Medicine 348, 891-899.

Baxter GJ, Graham AB, Lawrence JR, Wiles D \& Paterson JR (2001) Salicylic acid in soups prepared from organically- and non-organically grown vegetables. European Journal of Nutrition 40, 289-292.

Baxter GJ, Lawrence JR, Graham AB, Wiles D \& Paterson JR (2002) Identification and determination of salicylic acid and salicyluric acid in urine of people not taking salicylate drugs. Annals of Clinical Biochemistry 39, 50-55.

Baxter G, Paterson J, Wiles D, Graham A \& Shirastava R (2005) Salicylic acid: the spice of life? Proceedings of the Nutrition Society 64, 64A.

Benamouzig R, Deyra J, Martin A, Girard B, Jullian E, Piednoir B, Couturier D, Coste T, Little J \& Chaussade S (2003) Daily soluble aspirin and prevention of colorectal adenoma recurrence: one year results of the APACC trial. Gastroenterology 125, 328-336.

Blacklock CJ, Lawrence JR, Wiles D, Malcolm EA, Gibson IH, Kelly CJ \& Paterson JR (2001) Salicylic acid in the serum of subjects not taking aspirin. Comparison of salicylic acid concentrations in the serum of vegetarians, non-vegetarians, and patients taking low dose aspirin. Journal of Clinical Pathology 54, 553-555.

Bosetti C, Gallus S \& La Vecchia C (2001) Aspirin and cancer risk: an update to 2001. European Journal of Cancer Prevention 11, 535-542.

Craven PA \& DeRubertis FR (1992) Effects of aspirin on 1,2-dimethylhydrazine-induced colonic carcinogenesis. Carcinogenesis 13, 541-546.

Davidson C (1971) Salicylate metabolism in man. Annals of the New York Academy of Sciences 179, 249-268.

Duthie GG, Gardner PT \& Kyle JAM (2003) Plant polyphenols: are they the new magic bullet? Proceedings of the Nutrition Society 62, 599-603.

Duthie GG, Kyle JAM, Jenkinson AM, Duthie SJ, Baxter GJ \& Paterson JR (2005) Increased salicylate concentration in urine of human volunteers after consumption of cranberry juice. Journal of Agricultural and Food Chemistry 53, 2897-2900.

Fenoglio-Preiser CM \& Noffsinger A (1999) Aberrant crypt foci: A review. Toxicologic Pathology 27, 632-642.

Hare LG, Woodside JV \& Young IS (2003) Dietary salicylates. Journal of Clinical Pathology 56, 649-650.

Hawk LG, Umar A \& Viner JL (2004) Colorectal cancer chemoprevention - An overview of the science. Gastroenterology 128, 1423-1447.

Janssen PLTMK, Hollman PCH, Reichman E, Venema DP, van Staveren WA \& Katan MB (1996) Urinary salicylate excretion in subjects eating a variety of diets shows that the amount of bio-available salicylates is low. American Journal of Clinical Nutrition 64, 743-747.

Jeffreys D (2004) Aspirin: The Story of a Wonder Drug. London: Bloomsbury Publishing.
Lawrence JR, Peter R, Baxter GJ, Robson J, Graham AB \& Paterson JR (2003) Urinary excretion of salicyluric and salicylic acids in non-vegetarians, vegetarians and patients taking low dose aspirin. Journal of Clinical Pathology 56, 651-653.

Mahmoud MN, Dannenberg AJ, Mestre J, Bilinski RT, Churchill MR, Martucci C, Newmark H \& Bertagnolli MM (1998) Aspirin prevents tumors in a murine model of familial adenomatous polyposis. Surgery 124, 225-231.

Needs CJ \& Brooks PM (1985) Clinical pharmacokinetics of the salicylates. Clinical Pharmacokinetics 10, 164-177.

Nordic Committee on Food Analysis (1999) Salicylic Acid in Foods. Qualitative and Quantitative Analysis, NMKL Method no. 3, 3rd ed. Oslo, Norway: NMKL.

Paterson JR, Blacklock C, Campbell G, Wiles D \& Lawrence JR (1998) The identification of salicylates as normal constituents of serum: A link between diet and health? Journal of Clinical Pathology 51, 502-505.

Paterson JR \& Lawrence JR (2001) Salicylic acid: a link between aspirin, diet and the prevention of colorectal cancer. Quarterly Journal of Medicine 94, 445-448.

Pierpoint WS (2002) Can aspirin help identify leaf proteins active in defence responses? Annals of Applied Biology 140, 233-239.

Radtke J, Linseisen J \& Wolfram G (1998) Phenolic acid intake of adults in a Bavarian subgroup of the national food consumption survey. Zeitschrift für Ernahrungswissenschaft 37, 190-197.

Reddy BS, Rao CV, Rivenson A \& Kellof G (1993) Inhibitory effect of aspirin onazoxymethane-induced colon carcinogenesis in F344 rats. Carcinogenesis 14, 1493-1497.

Riboli E \& Norat T (2003) Epidemiologic evidence of the protective effect of fruit and vegetables on cancer risk. American Journal of Clinical Nutrition 78, 559S-569S.

Robertson GL \& Kermode WJ (1981) Salicylic acid in fresh and canned fruit and vegetables. Journal of the Science of Food and Agriculture 32, 833-836.

Sandler RS, Halabi S, Baron JA, Budinger S, Paskett E, Keresztes R et al. (2003) A randomised trial of aspirin to prevent colorectal adenomas in patients with previous colorectal cancer. New England Journal of Medicine 348, 883-890.

Scottish Collaborative Group (2005) Scottish Collaborative Group food frequency questionnaire. http://www.food frequency.org

Shpitz B, Bomstein Y, Kariv N, Shalev M, Buklan G \& Bernheim J (1998) Chemopreventative effect of aspirin on growth of aberrant crypt foci in rats. International Journal of Colorectal Diseases 13, 169-172.

Shpitz B, Klein E, Buklan G, Neufield D, Nissan A, Freund HR, Grankin M \& Berheim J (2003) Suppressive effect of aspirin on aberrant crypt foci in patients with colorectal cancer. Gut 52, 1598-1601.

Swain AR, Dutton SP \& Truswell AS (1985) Salicylates in foods. Journal of the American Dietetic Association 85, 950-960.

Venema DP, Hollman PCH, Janssen PLTMK \& Katan MB (1996) Determination of acetylsalicylic acid and salicylic acid in foods using HPLC with fluorescence detection. Journal of Agriculture and Food Chemistry 44, 1762-1767.

Wood A, Baxter G, Paterson J, Thies F \& Duthie G (2005) Comparison of methods to determine salicylic acid content of fruit juices. Proceedings of the Nutrition Society 64, 87A.

Wu KK (2000) Aspirin and salicylate - an old remedy with a new twist. Circulation 102, 2022-2023.

Xu XM, Sanores-Garcia L, Chen XM, Matijevic-Aleksic N, Du M \& Wu KK (1999) Suppression of inducible cyclooxygenase 2 gene transcription by aspirin and sodium salicylate. Proceedings of the National Academy of Sciences USA 96, 5292-5297. 